\title{
ЭФФЕКТИВНОСТЬ ПРИМЕНЕНИЯ БИОЛОГИЧЕСКОГО СТИМУЛЯТОРА «ГИПЕРГРИН» ПРИ ВОЗДЕЛЫВАНИИ ЯРОВОЙ ПШЕНИЦЫ В УСЛОВИЯХ КРАСНОЯРСКОЙ ЛЕСОСТЕПИ
}

\author{
N.L. Kurachenko, A.V. Sharopatova
}

\section{THE EFFICIENCY OF APPLICATION OF BIOLOGICAL STIMULATOR "HYPERGREEN" IN THE CULTIVATION OF SPRING WHEAT IN THE CONDITIONS OF KRASNOYARSK FOREST-STEPPE}

Кураченко Н.Л. - д-р биол. наук, проф., зав. каф. почвоведения и агрохимии Красноярского государственного аграрного университета, г. Красноярск.

E-mail: kurachenko@mail.ru

Шаропатова A.B. - канд. экон. наук, доц. каф. организации и экономики сельскохозяйственного производства Красноярского государственного аграрного университета, г. Красноярск.

E-mail: sharopatova@yandex.ru

В полевом опыте в условиях Красноярской лесостепи дана оценка эфрфективности биологического стимулятора «Гипергрин» при воздельвании яровой пшеницы сорта Новосибирская 15. Биологический стимулятор «Гипергрин» применялся в комплексной защите яровой пшеницы, где он использовался в качестве протравителя семян и в баковых смесях по вегетирующим растениям с гербицидами, фунгицидами и инсектицидами. Исследованиями показано, что эфрфективность применения препарата на посевах яровой пшеницы определяется погодными условиями. В условиях хорошей влагообеспеченности 2016 года биологический стимулятор при его использовании совместно с химическим протравителем и в баковых смесях по вегетирующим растениям способствует повышению урожайности яровой пшеницы на 10 ш/га $(p=0,02)$. Уровень рентабельности производства зерна яровой пшеницы при этом достигает $167 \%$. Биологическая стимуляция роста и развития растений яровой пшеницы в условия дефицита влаги (2017-2018 г2.) определяет повышение урожайности зерна пшеницы на 1-4 u/2а. Технология возделывания яровой пшеницы с применением "Гипергрина» совместно с протравителем и в баковых смесях по вегети-
Kurachenko N.L. - Dr. Biol. Sci., Prof., Head, Chair of Soil Science and Agrochemistry, Krasnoyarsk State Agrarian University, Krasnoyarsk.

E-mail: kurachenko@mail.ru

Sharopatova A.V. - Cand. Econ. Sci., Assoc. Prof., Chair of Organization and Agricultural Production Economics, Krasnoyarsk State Agrarian University, Krasnoyarsk.

E-mail: sharopatova@yandex.ru

рующим растениям в среднем за период испытаний определяет минимальную себестоимость продукции (514 руб/u), максимальную прибыль (317 руб/u) и рентабельность (62 \%). Способ применения биологического стимулятора «Гипергрин» в комплексной защите яровой пшеницы обусловливает структуру урожая культуры. Использование препарата для обработки семян в качестве протравителя и по вегетирующим растениям способствует повышению выживаемости растений к уборке на $11 \%$. Совместное использование биологического стимулятора с химическим протравителем и обработка посевов яровой пшеницы приводят к увеличению высоты растений на 4 см, количества колосков в колосе на 3 шт. по сравнению с контролем.

Ключевые слова: яровая пшеница, биологический стимулятор «Гипергрин», чернозем, структура урожая, урожайность, себестоимость, рентабельность.

The effectiveness of biological stimulator "Hypergreen" in the cultivation of spring wheat in Novosibirsk 15 variety was estimated in field experiment in the conditions of Krasnoyarsk foreststeppe. Biological stimulant "Hypergreen" was used in complex protection of spring wheat, where it was 
used as seed treatment and in the mixtures for vegetating plants with herbicides, fungicides and insecticides. The studies showed that the effectiveness of the stimulator on spring wheat crops had been determined by weather conditions. In the conditions of good moisture supply in 2016 biological stimulator when used together with chemical treatment and in mixtures for vegetating plants contributed to the increase in the yield of spring wheat by $10 \mathrm{c} /$ hectare $(p=0.02)$. The profitability level in grain production of spring wheat thus reached $167 \%$. Biological growth and development of the stimulation of spring wheat plants in conditions of moisture deficiency (2017-2018) determined the increase in wheat grain yield by 1-4 c/hectare. The cultivation technology of spring wheat with "Hypergreen" together with the treatment and in mixtures for vegetating plants on average during the test period determined the minimum cost of production (514 rubles/c), the maximum profit (317 rubles/c) and the profitability (62 \%). The application method of biological stimulant "Hypergreen" in the complex protection of spring wheat determined the crop structure. Using the preparation for seed processing as the treatment and for vegetative plants increased the survival rate of plants to yield by $11 \%$. Combined using of biological stimulator with chemical treatment and processing of spring wheat crops determined the increase in plant height by $4 \mathrm{~cm}$, the number of cones in the ear by 3 pieces compared with the control.

Keywords: spring wheat, biological stimulator "Hypergreen", chernozem, crop structure, yield, cost, profitability.

Введение. В последние годы все большее значение приобретает биологическая регуляция роста и развития сельскохозяйственных культур. Суровые климатические условия земледельческой части Красноярского края усугубляются обострением экономических и экологических проблем в сельском хозяйстве, снижением объемов внесения минеральных и органических удобрений. При этом задача повышения продуктивности культур остается по-прежнему актуальной. Особенно важным становится освоение агроприемов, обеспечивающих формирование урожая независимо от колебаний погодных условий, с низкими затратами труда и финансов.
Применение биостимуляторов является одним из способов повышения продуктивности растений и получения высококачественной продукции, способствующей более полной реализации продукционного потенциала современных сортов [1-3]. Регуляторы роста растений оказывают влияние не только на продуктивное использование подвижных форм минеральных веществ растениями, но и повышают устойчивость растений к стрессам, болезням, вредителям [4]. Они являются мощным средством управления онтогенезом растений и находят широкое применение в технологии возделывания сельскохозяйственных растений [5]. В настоящее время отечественный рынок интенсивно пополняется новыми гуминовыми препаратами, данная ситуация ставит перед наукой задачу поиска новых областей их применения и исследований потенциальных рисков.

Цель исследований. Оценить эффрективность применения биологического стимулятора «Гипергрин» при возделывании яровой пшеницы в условиях Красноярской лесостепи

Объекты и методы исследований. Исследования по оценке эффрективности применения биологического стимулятора «Гипергрин» («HYPERGREEN») были проведены в 20162018 гг. в полевом опыте учебного хозяйства «Миндерлинское» Красноярского государственного аграрного университета в Красноярской лесостепи (56 ${ }^{\circ}$ с.ш., $92^{\circ}$ в.д.). Объекты исследования - комплекс черноземов выщелоченных и обыкновенных; пшеница сорта Новосибирская 15, идущая по предшественникам - картофеель (2016 г.) и соя (2017-2018 гг.); биологический стимулятор «Гипергрин» (Гумилайф GSN-A). «Гумилайф GSN-A» относился ко второму поколению биологических стимуляторов роста растений. «Гипергрин» - это третье поколение биологических стимуляторов роста растений. Изменена технология получения препарата. Из одного и того же сырья получен коктейль гуминовых кислот, которые действуют на разные части растений: корневую систему (ГиперСтарт), листовой аппарат (ГиперРост).

Черноземы выщелоченные и обыкновенные опытного поля характеризовались тяжелосуглинистым гранулометрическим составом с высоким и очень высоким содержанием гумуса $(8,6-11,1 \%)$, нейтральной реакцией среды 
$\left(\mathrm{pH}_{\text {н2О }}-6,7-6,9\right)$, высокой суммой обменных оснований (55-62 мг-экв/100 г). В пахотном слое черноземов содержалось: $\mathrm{P}_{2} \mathrm{O}_{5}-$ 152,0-316,0 мг/кг, К $\mathrm{K}_{2} \mathrm{O}-178,0-288,0 \mathrm{мг/ \kappa г.}$

Схема полевого опыта в 2016 году включала в себя следующие варианты: 1. Контроль (Магнум Супер (10 г/га) + Ластик Экстра, КЭ (1 л/га)). 2. Виал ТрасT, ВC (0,4 л/т) + Гумилайф GSN-A $(0,5$ л/т) - Магнум Супер (10 г/га) + Ластик Экстpa, КЭ (1 л/га) + Гумилайф GSN-A (0,3 л/т) - Зенон Аэро, КЭ (1 л/га) + Цунами, КЭ $(0,15$ л/га) + Гумилайф GSN-A (2л/га). 3. Гумилайф GSN-A $(0,5$ л/т) - Магнум Супер (10 г/га) + Ластик Экстра, КЭ (0,85 л/га) + Гумилайф GSN-A $(0,3$ л/т) Зенон Аэро, КЭ (1 л/га) + Цунами, КЭ $(0,15$ л/га) + Гумилайф GSN-A (2 л/га).

В полевой сезон 2017-2018 гг. исследование проведено с препаратом нового поколения по схеме: 1. Контроль (Оплот, ВСК (0,5 л/т) - Магнум Супер (10 г/га) + Ластик Экстра, КЭ (1 л/га) Зенон Аэро, КЭ (1 л/га) + Цунами, КЭ (0,15 л/га). 2. Оплот, ВСК $(0,5 \pi / \tau)+$ ГиперСтарт $(0,5 \pi / \tau)-$ Магнум Супер (10 г/га) + Ластик Экстра, КЭ (1 л/га) + ГиперРост $(0,3$ л/т) - Зенон Аэро, КЭ (1 л/га) + Цунами, КЭ $(0,15$ л/га) + ГиперРост (2л/га). 3. ГиперСтарт (0,5 л/т) - Магнум Супер (10 г/га) + Ластик Экстра, КЭ $(0,85$ л/га) + ГиперРост $(0,3$ л/т) - Зенон Аэро, КЭ (1 л/га) + Цунами, КЭ (0,15 л/га) + ГиперРост (2 л/га).

Минеральные удобрения в опытах не применялись. Доза каждого из используемых препаратов соответствовала рекомендациям производителя. Предпосевная обработка семян осуществлялась за один день до посева. Первая внекорневая обработка пшеницы биологическим стимулятором проводилась в фазе кущения в баковой смеси с гербицидами. Вторая внекорневая обработка пшеницы осуществлялась в фазе выхода в трубку - колошения в баковой смеси с фунгицидами и инсектицидами.

Определение густоты стояния растений перед уборкой и отбор снопов для определения структуры урожая проводили на площади 1 м² в 3-кратной повторности. Учет урожая проводили в 4-кратной повторности пробными площадями

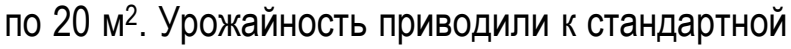
14\%-й влажности и 100\%-й чистоте.

Статистическая обработка полученных результатов проведена методами дисперсионного анализа и описательной статистики [6] с использованием программы Microsoft Excel XP.

Результаты исследований и их обсуждение. Для производства сельскохозяйственной продукции необходимы такие технологии и технологические приемы формирования и функционирования агроценозов, которые в конкретных почвенно-климатических условиях дадут более высокий экономический эффрект в сочетании с природоохранными функциями. Высокая биологическая активность гуминовых веществ несомненно играет важную роль в обеспечении как биологической продуктивности системы почва-растение, так и ее устойчивости к неблагоприятным воздействиям. Исследования, проведенные в годы, существенно отличающиеся по влагообеспеченности, показали, что эфффективность биологического стимулятора «Гипергрин» определялась фактором «погодные условия». Вегетационный сезон 2016 года характеризовался как теплый, с достаточным увлажнением. С июня по август температура была на 1-2 ${ }^{\circ} \mathrm{C}$ выше многолетних показателей. Сумма осадков за майский период превышала среднемноголетние значения на $36 \%$. Июльский и августовский периоды были близкими к среднемноголетним данным. Условия сезона 2017 года отличались хорошей теплообеспеченностью с неравномерным увлажнением летних месяцев. Особенно критическим для роста и развития растений оказался июнь. В этот месяц при средней температуре воздуха, превышающей среднемноголетние показатели на $5{ }^{\circ} \mathrm{C}$, выпало всего 20 мм осадков (18 мм в третьей декаде июня), что ниже нормы на 50 \%. Вегетационный сезон 2018 года отличался теплой погодой и острозасушливыми условиями. В июле и августе при средней температуре воздуха, близкой к среднемноголетнему значению, выпало всего 15-21 мм осадков соответственно, что ниже нормы на 78-66 \%.

При разработке технологии возделывания, направленной на оптимальное развитие каждого элемента, необходимо учитывать, что урожай формируется за счет различных элементов, степень выраженности которых может быть разной. Слабое развитие одного элемента структуры урожая может быть компенсировано за счет других. Установлено, что биологический стимулятор «Гипергрин» при различных спосо- 
бах его применения оказал влияние на некоторые элементы структуры урожая яровой пшеницы (табл. 1). Применение стимулятора в качестве протравителя семян и для обработки вегетирующих посевов определило увеличение количества выживших к уборке растений в среднем за годы исследований на $11 \%$ по сравнению с контролем. Совместное использование «Гипергрина» с химическим протравителем на семенах и в баковых смесях с гербицидами и инсектицидами способствовало увеличению высоты растений на 4 см, количества колосков на 3 шт.

\section{Влияние биологического стимулятора «Гипергрин» на элементы структуры урожая яровой пшеницы (2016-2018 гг.)}

\begin{tabular}{|l|c|c|c|c|}
\hline \multicolumn{1}{|c|}{ Вариант } & $\begin{array}{c}\text { Количество рас- } \\
\text { тений к уборке, } \\
\text { шт/м² }\end{array}$ & $\begin{array}{c}\text { Высота } \\
\text { растений, } \\
\text { см }\end{array}$ & $\begin{array}{c}\text { Длина } \\
\text { колоса, } \\
\text { см }\end{array}$ & $\begin{array}{c}\text { Количество } \\
\text { колосков, } \\
\text { шт. }\end{array}$ \\
\hline Контроль (химическая защита) & 358 & 79 & 7 & 35 \\
\hline $\begin{array}{l}\text { «Гипергрин» совместно с протра- } \\
\text { вителем и в баковых смесях по } \\
\text { вегетирующим растениям }\end{array}$ & 351 & 83 & 7 & 38 \\
\hline $\begin{array}{l}\text { «Гипергрин» в качестве протрави- } \\
\text { теля и в баковых смесях по веге- } \\
\text { тирующим растениям }\end{array}$ & 398 & 77 & 7 & 35 \\
\hline
\end{tabular}

Достаточное увлажнение вегетационного сезона 2016 года обусловило максимальную урожайность яровой пшеницы. Использование биологического стимулятора «Гипергрин» для протравливания семян и обработки посевов в фазу кущения и выхода в трубку-колошения способствовало повышению урожайности яровой пшеницы на 3-10 ц/га ( $p=0,02)$ (рис.). Выявлено, что при несущественном варьировании урожайности в выборках (Cv = 2-10\%) максимальный уровень продуктивности яровой пшеницы установлен на варианте с использованием «Гипергрина» в качестве протравителя в чистом виде с последующими внекорневыми обработками посевов пшеницы (45 ц/га). Максимальная продуктивность яровой пшеницы в засушливый 2017 год была сформирована на этом же варианте опыта (33 ц/га). Однако отмеченная в опыте тенденция повышения урожайности пшеницы математически не доказывалась ( $p=0,56)$. Применяемые в опыте технологии комплексной защиты яровой пшеницы показали близкий уровень продуктивности и в острозасушливый вегетационный сезон 2018 года $(p=0,33)$.

Анализ литературных источников по эффективности гуминовых препаратов на зерновых культурах позволяет утверждать, что их применение дает возможность увеличивать урожай- ность по сравнению с контролем. Однако величина прибавок достаточно сильно варьирует по годам, что обусловлено погодными условиями. Так, исследованиями [7-8] показано, что засушливые погодные условия вегетационных периодов существенно снижали эфффективность биологических стимуляторов на посевах зерновых культур. Внесение в почву гуминовых удобрений и препаратов способствует росту микробиологической активности, возрастает потребление органических и минеральных субстратов. Все это увеличивает минерализацию органических веществ, разрушение почвенных минералов. Как следствие, наблюдается высвобождение элементов минерального питания, которые активно потребляются растениями. В этом и заключается опосредованное воздействие гуминовых веществ на растения через почвенную микрофрлору. Следует подчеркнуть, что растения с корневыми выделениями поставляют в почву органические кислоты, способствующие активизации микрофолоры, разложению минерального субстрата и высвобождению элементов питания, обеспечивая «ризосферный эффект» [9]. По мнению О.С. Безугловой, Е.А. Полиенко [10], за счет внесения биологически активных веществ происходит активизация биохимических процессов в почве и повышается 
доступность элементов питания. При низкой биологической активности, вызванной недостатком влаги в связи с засухой, наблюдается замирание процессов минерализации и гумификации в почве. Подобная закономерность отмечена нами при применении микробиологического удобрения «Азофит» в технологии возделывании рапса на маслосемена [11].
Одной из важнейших оценок применения биопрепаратов и регуляторов роста является определение их экономической эффективности. Применение биологического стимулятора «Гипергрин» в технологии возделывания яровой пшеницы увеличивало прибыль и рентабельность и снижало себестоимость продукции (табл. 2).

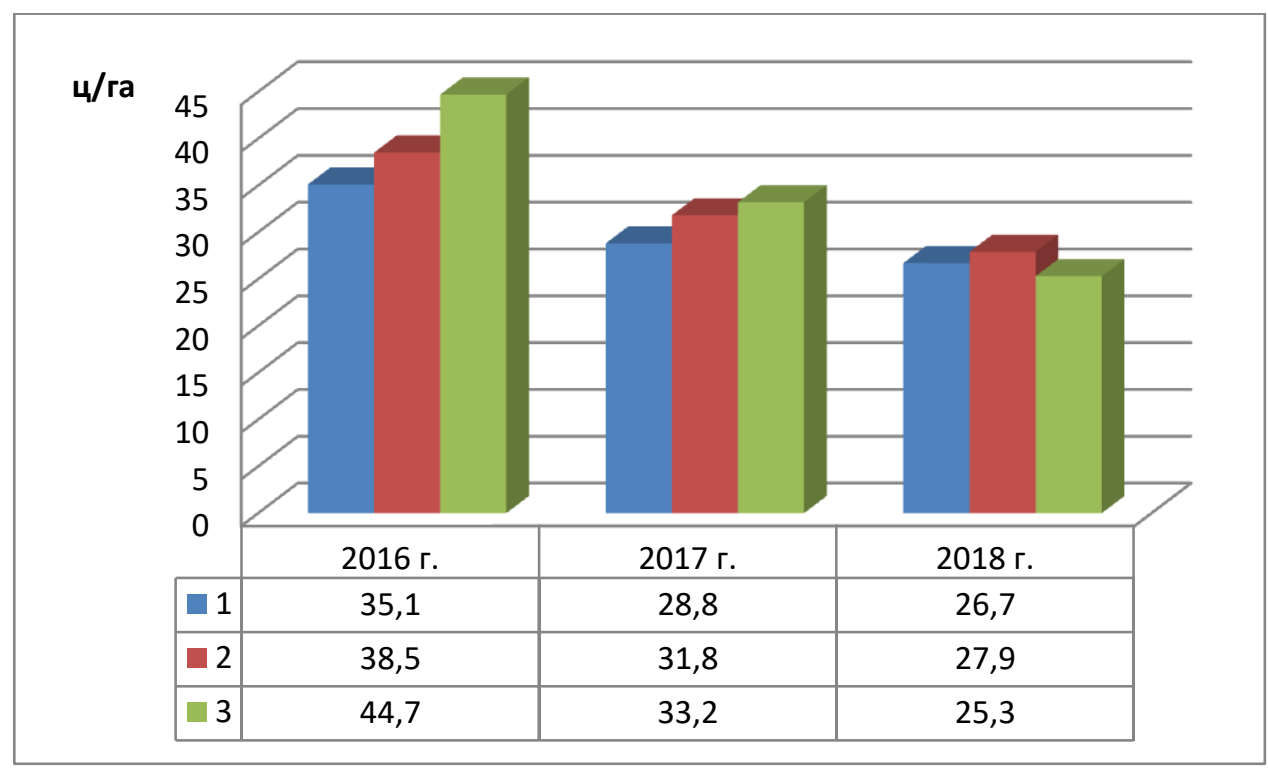

Урожайность яровой пшеницы Новосибирская 15 на вариантах опыта: 1 - контроль (химическая защита); 2 - «Гипергрин» совместно с протравителем и в баковых смесях по вегетирующим растениям; 3 - «Гипергрин» в качестве протравителя и в баковых смесях по вегетирующим растениям, и/га

Таблица 2

Показатели экономической эффективности производства зерна яровой пшеницы

\begin{tabular}{|l|c|c|c|c|}
\hline \multirow{2}{*}{ Показатель } & \multicolumn{3}{|c|}{ Год } & \multirow{2}{*}{$\begin{array}{c}\text { В среднем } \\
\text { за 3 года }\end{array}$} \\
\cline { 2 - 5 } & 2016 & 2017 & 2018 & 5 \\
\hline \multicolumn{1}{|c|}{ Контроль } & 3 & 4 & \\
\hline $\begin{array}{l}\text { Посевная площадь зерновых куль- } \\
\text { тур, га }\end{array}$ & 100 & 100 & 100 & 100 \\
\hline Урожайность, ц с 1 га & 35,1 & 28,8 & 26,7 & 30,2 \\
\hline $\begin{array}{l}\text { Затраты средств на 1 га посева } \\
\text { зерновых культур, руб. }\end{array}$ & 15077,5 & 15785,5 & 17553,2 & 16138,7 \\
\hline $\begin{array}{l}\text { Себестоимость производства 1 ц } \\
\text { зерна, руб. }\end{array}$ & 452,2 & 577,0 & 692,0 & 534,4 \\
\hline $\begin{array}{l}\text { Средняя цена реализации 1 ц } \\
\text { зерна, руб. }\end{array}$ & 936,4 & 820,2 & 735,3 & 830,6 \\
\hline
\end{tabular}


Вестник КрасТАУ. 2019. № 12

\begin{tabular}{|c|c|c|c|c|}
\hline \multicolumn{5}{|c|}{ Окончание табл. 2} \\
\hline 1 & 2 & 3 & 4 & 5 \\
\hline Прибыль на 1 ц зерна, руб. & 484,2 & 243,2 & 43,3 & 296,2 \\
\hline $\begin{array}{l}\text { Получено прибыли на } 1 \text { га пшени- } \\
\text { цы, руб. }\end{array}$ & 16995,4 & 7004,2 & 1156,1 & 8945,4 \\
\hline $\begin{array}{l}\text { Уровень } \\
\text { рентабельности производства зер- } \\
\text { на, \% }\end{array}$ & 107,1 & 42,2 & 6,3 & 55,4 \\
\hline \multicolumn{5}{|c|}{$\begin{array}{c}\text { «Гипергрин» совместно с протравителем и в баковых смесях } \\
\text { по вегетирующим растениям }\end{array}$} \\
\hline $\begin{array}{l}\text { Посевная площадь зерновых куль- } \\
\text { тур, га }\end{array}$ & 100 & 100 & 100 & 100 \\
\hline Урожайность, ц с 1 га & 44,7 & 33,2 & 25,3 & 34,4 \\
\hline $\begin{array}{l}\text { Затраты средств на } 1 \text { га посева } \\
\text { зерновых культур, руб. }\end{array}$ & 14901,5 & 15128,6 & 16445,2 & 15491,7 \\
\hline $\begin{array}{l}\text { Себестоимость производства } 1 \text { ц } \\
\text { зерна, руб. }\end{array}$ & 350,9 & 479,7 & 684,2 & 450,3 \\
\hline $\begin{array}{l}\text { Средняя цена реализации } 1 \text { ц зер- } \\
\text { на, руб. }\end{array}$ & 936,4 & 820,2 & 735,3 & 830,6 \\
\hline Прибыль на 1 ц зерна, руб. & 585,5 & 340,5 & 51,1 & 380,3 \\
\hline $\begin{array}{l}\text { Получено прибыли на } 1 \text { га пшени- } \\
\text { цы, руб. }\end{array}$ & 26171,9 & 11304,6 & 1292,8 & 13080,9 \\
\hline $\begin{array}{l}\text { Уровень рентабельности производ- } \\
\text { ства зерна, \% }\end{array}$ & 166,9 & 71,0 & 7,5 & 84,4 \\
\hline \multicolumn{5}{|c|}{ «Гипергрин» в качестве протравителя и в баковых смесях по вегетирующим растениям } \\
\hline $\begin{array}{l}\text { Посевная площадь зерновых куль- } \\
\text { тур, га }\end{array}$ & 100 & 100 & 100 & 100 \\
\hline Урожайность, ц с 1 га & 38,5 & 31,8 & 27,9 & 32,7 \\
\hline $\begin{array}{l}\text { Затраты средств на } 1 \text { га посева } \\
\text { зерновых культур, руб. }\end{array}$ & 14984,9 & 15392,2 & 16788,2 & 15721,7 \\
\hline $\begin{array}{l}\text { Себестоимость производства } 1 \text { ц } \\
\text { зерна, руб. }\end{array}$ & 409,7 & 509,7 & 633,4 & 480,8 \\
\hline $\begin{array}{l}\text { Средняя цена реализации } 1 \text { ц зер- } \\
\text { на, руб. }\end{array}$ & 936,4 & 820,2 & 735,3 & 830,6 \\
\hline Прибыль на 1 ц зерна, руб. & 526,7 & 310,5 & 101,9 & 349,8 \\
\hline $\begin{array}{l}\text { Получено прибыли на } 1 \text { га пшени- } \\
\text { цы, руб. }\end{array}$ & 20278,0 & 9873,9 & 2843,0 & 11439,8 \\
\hline $\begin{array}{l}\text { Уровень рентабельности производ- } \\
\text { ства зерна, \% }\end{array}$ & 128,6 & 60,9 & 16,1 & 72,8 \\
\hline
\end{tabular}

Наилучшие показатели экономической эффективности были получены в 2016 году при использовании биологического стимулятора «Гипергрин» совместно с химическим протравителем Виал ТрасТ, ВС и при двукратном его применении в баковых смесях по вегетирующим растениям, где уровень рентабельности производства зерна яровой пшеницы составил $167 \%$. Применение технологии возделывания яровой пшеницы с использованием «Гипергрин» совместно с протравителем и в баковых смесях по вегетирующим растениям в среднем за период испытаний определило минимальную себестоимость продукции (450,3 руб/ц), максимальную прибыль (380 руб/ц) и рентабельность (84 \%).

Выводы. Способ применения биологического стимулятора «Гипергрин» в комплексной защите яровой пшеницы определяет структуру 
урожая культуры. Использование препарата для обработки семян в качестве протравителя и по вегетирующим растениям способствует повышению выживаемости растений к уборке на $11 \%$. Совместное использование биологического стимулятора с химическим протравителем и обработка посевов яровой пшеницы определяют увеличение высоты растений на 4 см, количества колосков в колосе на 3 шт. по сравнению с контролем. Использование биологического стимулятора для предпосевной обработки семян и посевов в фазу кущения и выхода в трубкуколошения пшеницы способствует повышению её урожайности на 1-10 ц/га в различные годы. Максимальная экономическая эффективность препарата установлена в достаточно увлажненный 2016 год при использовании биологического стимулятора «Гипергрин» совместно с химическим протравителем и двукратном его применении в баковых смесях по вегетирующим растениям. Уровень рентабельности производства зерна яровой пшеницы составил $167 \%$.

\section{Литература}

1. Жеребцов С.И., Мальшенко Н.В., Лырщиков С.Ю. [и др.]. Состав и биологическая активность гуматов бурого угля как стимуляторов роста сельскохозяйственных культур // Вестник Кузбасского государственного технического университета. - 2014. - № 5 (105). - C. 102-106.

2. Борисенко В.В., Хусид С.Б. Изучение влияния обогащенного биогумата «ЭКОСС» на продуктивность овощных культур // Политематический сетевой электронный научный журнал Кубанского государственного аграрного университета. - 2015. - № 107 (03). C. 86-93.

3. Васин В.Г., Вершинина О.В., Лысак О.Н. Влияние применения биостимуляторов «Фертигрейн» на структуру урожая и продуктивность гороха и нута // Известия Самарской государственной сельскохозяйственной академии. - 2015. - № 4. - С. 3-7.

4. Ерохин А.И. Эффрективность действия новых препаратов фиторегуляторов на рост, развитие растений и урожайность гороха // Зернобобовые и крупяные культуры. 2013. - № 2 (6). - 120 C.
5. Аленин П.Г., Кшникаткина А.Н. Продукционный потенциал зерновых, зернобобовых, кормовых, лекарственных культур и совершенствование технологии их возделывания в лесостепи Среднего Поволжья. - Пенза, 2012. - $265 \mathrm{c}$.

6. Дмитриев Е.А. Математическая статистика в почвоведении. - М.: Изд-во МГУ, 1995. $319 \mathrm{c}$.

7. Виноградова В.С., Лучник Н.А., Хитрова В.И. Влияние внекорневой обработки посевов гуминовыми удобрениями и мочевиной на урожай яровой пшеницы и его качество // Аграрная наука Евро-СевероВостока. - 2012. - № 4. - С. 31-35.

8. Комарова Г.Н., Сорокина А.В. Влияние гуминового удобрения из торфа «Гумостим» на урожайность и качество зерна овса // Сибирский вестник сельскохозяйственной науки. - 2015. - № 5. - С. 12-18.

9. Warembourg F.R. The 'rhizosphere effect: a plant strategy for plants to exploit and colonize nutrient-limited habitats // Bocconea. - 1997. № 7. - P. 187-193.

10. Безуглова О.С., Полиенко Е.А. Применение гуминовых препаратов под картофель и озимую пшеницу // Проблемы агрохимии и экологии. - 2011. - № 4. - С. 29-32.

11. Кураченко Н.Л., Халипский А.Н., Казанов В.В. Влияние микробиологического удобрения «Азофит» на агрофизическое состояние чернозема и продуктивность рапса, возделываемого на маслосемена // Вестник КрасГАУ. - 2019. - № 3. - С. 22-28.

\section{Literatura}

1. Zherebcov S.I., Malyshenko N.V., Lyrshhikov S.Ju. [i dr.]. Sostav i biologicheskaja aktivnost' gumatov burogo uglja kak stimuljatorov rosta sel'skohozjajstvennyh kul'tur // Vestnik Kuzbasskogo gosudarstvennogo tehnicheskogo universiteta. - 2014. № 5 (105). - S. 102-106.

2. Borisenko V.V., Husid S.B. Izuchenie vlijanija obogashhennogo biogumata "JeKOSS» na produktivnost' ovoshhnyh kul'tur // Politematicheskij setevoj jelektronnyj nauchnyj zhurnal Kubanskogo gosudarstvennogo agrarnogo universiteta. - 2015. - № 107 (03). S. 86-93. 
3. Vasin V.G., Vershinina O.V., Lysak O.N. Vlijanie primenenija biostimuljatorov "Fertigrejn» na strukturu urozhaja i produktivnost' goroha i nuta //lzvestija Samarskoj gosudarstvennoj sel'skohozjajstvennoj akademii. 2015. - № 4. - S. 3-7.

4. Erohin A.I. Jeffektivnost' dejstvija novyh preparatov fitoreguljatorov na rost, razvitie rastenij i urozhajnost' goroha // Zernobobovye i krupjanye kul'tury. - 2013. - № 2 (6). - 120 c.

5. Alenin P.G., Kshnikatkina A.N. Produkcionnyj potencial zernovyh, zernobobovyh, kormovyh, lekarstvennyh kul'tur i sovershenstvovanie tehnologii in vozdelyvanija $v$ lesostepi Srednego Povolzh'ja. - Penza, 2012. - 265 s.

6. Dmitriev E.A. Matematicheskaja statistika v pochvovedenii. - M.: Izd-vo MGU, 1995. - 319 s.

7. Vinogradova V.S., Luchnik N.A., Hitrova V.I. Vlijanie vnekornevoj obrabotki posevov guminovymi udobrenijami i mochevinoj na urozhaj jarovoj pshenicy i ego kachestvo //
Agrarnaja nauka Evro-Severo-Vostoka. 2012. - № 4. - S. 31-35.

8. Komarova G.N., Sorokina A.V. Vlijanie guminovogo udobrenija iz torfa Gumostim na urozhajnost' i kachestvo zerna ovsa // Sibirskij vestnik sel'skohozjajstvennoj nauki. - 2015. № 5. - S. 12-18.

9. Warembourg F.R. The 'rhizosphere effect: a plant strategy for plants to exploit and colonize nutrient-limited habitats // Bocconea. - 1997. № 7. - P. 187-193.

10. Bezuglova O.S., Polienko E.A. Primenenie guminovyh preparatov pod kartofel' i ozimuju pshenicu // Problemy agrohimii i jekologii. 2011. - № 4. - S. 29-32.

11. Kurachenko N.L., Halipskij A.N., Kazanov V.V. Vlijanie mikrobiologicheskogo udobrenija «Azofit» na agrofizicheskoe sostojanie chernozema i produktivnost' rapsa, vozdelyvaemogo na maslosemena // Vestnik KrasGAU. - 2019. - № 3. - S. 22-28. 